\title{
Crackdown on factory farm drug use urged
}

$\mathrm{T}$ he federal government must crackdown on the use of antibiotics such as cephalosporins and fluoroquinolones within the nation's meat industry because of the threat that antibiotic resistance poses to public health, says one of the government's leading veterinary drug safety officials.

"The writing is on the wall," Manisha Mehrotra, director of the human safety division within Health Canada's Veterinary Drugs Directorate, told a conference on veterinary antimicrobial stewardship in Toronto, Ontario, in November 2011. "We can no longer have these medically important drugs [available to meat producers] over the counter. ... We are considering moving to make all the drugs that are medically important available only on prescription. And we are considering rereviewing all drugs approved before 2004. There needs to be regulatory amendment."

That will necessitate a prohibition on the use of cephalosporins and fluoroquinolones without direct veterinary supervision, Mehrota said.

Yet, achieving that will require substantial changes at the veterinary drugs directorate itself and resolution of jurisdictional conflicts with the provinces.

Mehorta noted that independent assessments indicate that federal oversight of antibiotic use in factory farms is dismal. Health Canada has fallen behind the United States Food and Drug Administration (FDA) in reforming regulations governing food industry use of human drugs, she said. "I feel like we've been handed a B minus and an F. ... The time is right to have these solutions in Canada as well."

"Modernization" of the directorate will be required, she added, noting that Canada has fallen behind the United States on several fronts, including the use fluoroquinolones (along with cephalosporins) in poultry. A recent surveillance report from the Public Health Agency of Canada's (PHAC) Canadian Integrated Pro-

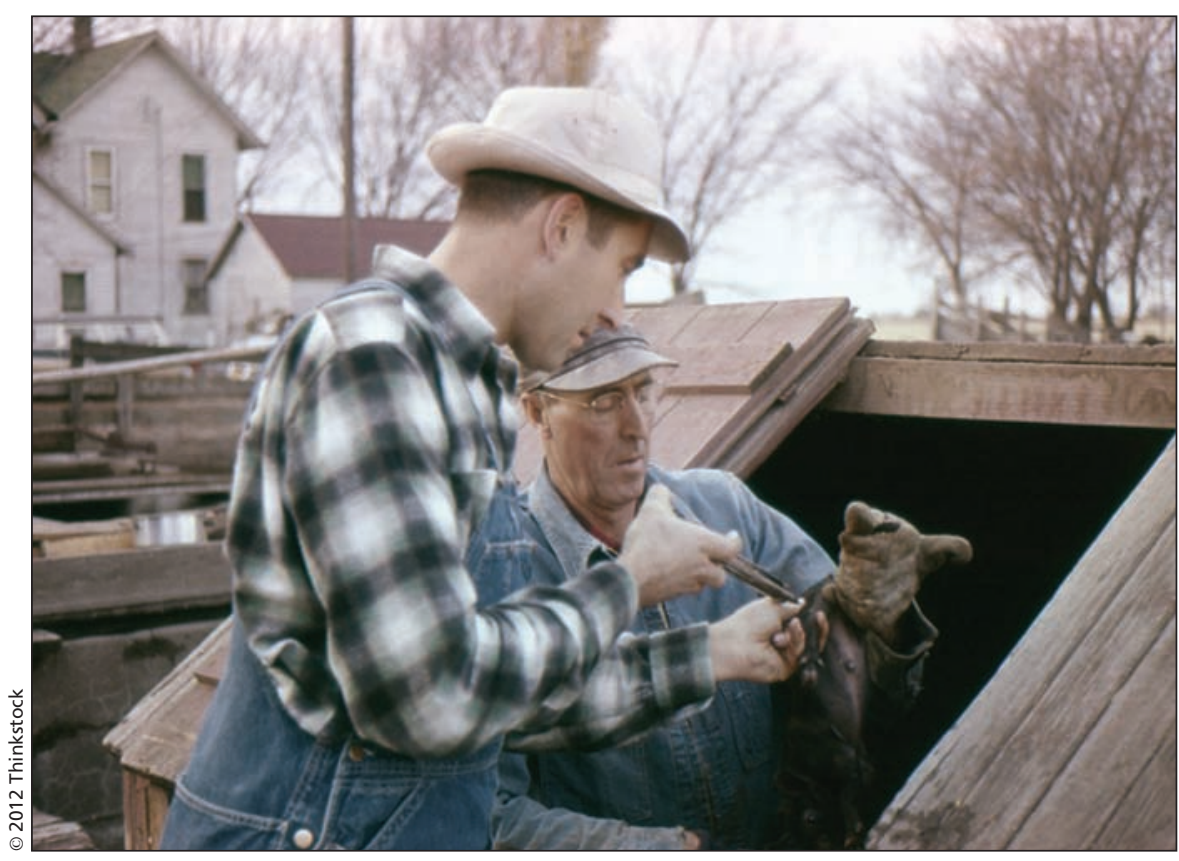

Direct veterinary supervision would be required to inject animals with cephalosporins and fluoroquinolones if the federal and provincial governments move to restrict over the counter use of the antibiotics.

gram for Antibiotic Resistance Surveillance (CIPARS) has raised new concerns about the use of fluoroquinolones among British Columbia and Saskatchewan chicken farms (www .phac-aspc.gc.ca/cipars-picra/2008/index -eng.php,).

Two proposed laws currently before the US Congress - "The Preservation of Antibiotics for Medical Treatment Act" and "The Strategies to Address Antimicrobial Resistance Act" would phase out the use of seven classes of drugs for growth promotion and routine disease prevention in food animals, unless drug makers demonstrate such use is safe. They would also compel the FDA to collect, compile and publish antibiotic sales data, as well as bolster antibiotic resistance surveillance and oversight.

Alarms have long been sounded over Canadian management of antibiotic resistance (www.cmaj.ca/lookup/doi /10.1503/cmaj.109-3109). Critics have charged that the federal government has failed to tighten off-label drug usage on farms (www.cmaj.ca/lookup/doi/10 $.1503 /$ cmaj.091009) or to close a legal loophole that allows massive imports of unapproved drugs (www.cmaj.ca /lookup/doi/10.1503/cmaj.090525).

In reforming oversight, federal officials also indicated that there is a need to compel industry disclosure about the extent of their use of cephalosporins and fluoroquinolones, which experts say is contributing to the spread of antibiotic-resistant bacteria. While the Canadian Food Inspection Agency can review some data on drug use, industry can block its release on the grounds that it is commercially confidential, says Ashwani Tiwari, acting national manager of epidemiology and risk mitigation for the agency.

"We are often in the dark" about the extent of drug use, including off-label use, adds Rebecca Irwin, chief scientist for CIPARS. "We have fractured, sparse data."

Conducting public health surveillance without drug use data is "like flying without flying," added Richard 
Reid Smith, a veterinary epidemiologist with PHAC's Laboratory for Foodborne Zoonoses, in Guelph, Ontario.

In light of industry's refusal to provide data on drug use, David White, director of research at the US Food and Drug Administration's Center for Veterinary Medicine, recommended that Canadian surveillance officials bolster whole-genome sequencing capacity, which would allow investigators to track resistance in humans to specific sources within the meat and poultry.

White told the Toronto gathering that the CIPARS data is viewed by the FDA as a "real red flag," He added that the ability of bacteria to become antibiotic resistant is "like a snowball rolling down a hill. These things keep accumulating new genes."
Proper regulation of meat industry use of antibiotics will also require resolving jurisdictional issues with the provinces.

Meat production is currently regulated under provincial laws that fail to address the growing problem with antibiotic resistance driven by drug misuse, explains David Léger, a veterinary epidemiologist with CIPARS. The vast majority of regulations in Canada are geared toward lowering drug residues in meat rather than protecting against antibiotic resistance, he says, adding that Quebec is the sole province that requires the prescription-only usage of human drugs in animals.

A Council of Canadian Academies panel recently called for an "integrated, multidimensional approach" toward government risk assessment of drug use in food production (www.scienceadvice .ca/uploads/eng/assessments\%20and\% 20publications $\% 20$ and $\% 20$ news $\% 20$ releases/animal\%20health/final_ah_web _report_eng.pdf). But completely absent from the panel's report was any mention of the threat to human health posed by increasing antimicrobial resistance among livestock (www.cmaj.ca/lookup /doi/10.1503/cmaj.109-4039).

Dr. Alastair Cribb, panel chair and dean of the Faculty of Veterinary Medicine at the University of Calgary in Alberta, says the need for improved risk assessments is imperative. "And this needs to happen sooner rather than later." - Paul Christopher Webster, Toronto, Ont.

CMAJ 2012. DOI:10.1503/cmaj.109-4055 